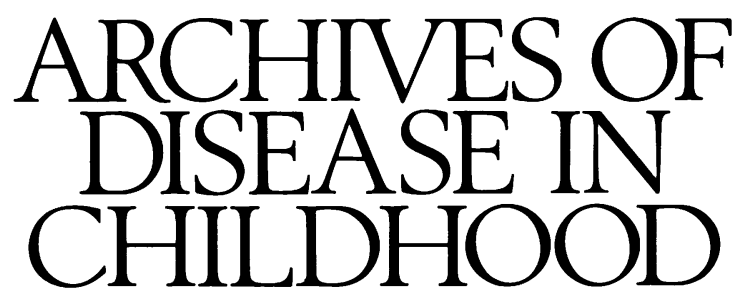

The fournal of the British Paediatric Association

\title{
Annotations
}

\section{Posterior rootlet rhizotomy in cerebral palsy}

As a neurosurgical method to reduce spasticity in cerebral palsy, Peacock and Arens brought posterior rootlet rhizotomy from South Africa to California about 1985. ${ }^{12}$ The procedure fell on fertile ground in the United States and spread to at least 30 medical centres in the 50 states from Arkansas to Washington. ${ }^{3-5}$ In addition, several centres in Canada offer the operation.

\section{From theory to practice}

In 1898 Sherrington described relief of muscle spasticity by posterior root section in decerebrate cats. ${ }^{6}$ The hypothesis formed was that the basis for motor control and muscle tone is due to the balance of two opposing forces acting on the anterior horn cell. One is facilitation of muscle contraction via the afferent fibres from the muscle spindle intrafusal sensing fibres that enter the cord through the posterior roots. The other is inhibition of the muscle contraction via the descending tracts from the brain. This concept holds that spastic paralysis is the result of central neuron damage that reduces the higher level of inhibition. The reduced inhibition effect causes excessive spinal anterior horn cell activity with resultant spasticity of the limb muscles. The application of the theory is to cut the posterior roots of the spinal cord to diminish the facilatory influences on the motor neuron. The result is reduction of the spasticity of the muscles.

In 1913 Foerster used this theoretical basis in performing posterior root rhizotomy for the relief of spasticity in the lower limb muscles. ${ }^{7}$ Using electrical stimulation he identified and cut the posterior roots from L2 to S2, but spared the L4 root to preserve the quadriceps and the ability to stand. Foerster termed 88 of his 150 cases, 'congenital spastic paraplegia' and eight as 'infantile spastic paraplegia'. While not documenting all his results, he published case reports with photographs that depicted dramatic improvement in function and limb position. He emphasised that to restore voluntary mobility after this surgery, a long exercise treatment programme was necessary and mentioned that the patients often required orthopaedic procedures.

\section{Resurrection of posterior rhizotomy in cerebral palsy}

A half century elapsed before interest in rhizotomy for cerebral palsy was rekindled. The reason usually given for this hiatus is that the postoperative sensory loss was frequent or the spasticity returned. Most authors attribute the resurrection of posterior rhizotomy for spastic paralysis in 1967 to Gros and colleagues of Montpelier, France. They did posterior rhizotomies by cutting only four fifths of the rootlets from L1 to S1. ${ }^{8}$ In 1979 Gros reported 62 cases with an 18 year follow up; a $25 \%$ failure rate occurred. He attributed failure to errors in selection. Twenty two had relative hypoaesthesia in some limb areas. Of the 25 cases of cerebral palsy, he noted improved speech and upper limb function postoperatively. ${ }^{9}$

Fasano et al of Italy in 1978 introduced 'selective' posterior rootlet rhizotomy for cerebral palsy patients by intraoperative stimulation of the rootlets to decide by electromyographic recording which ones should be cut to reduce the spasticity. ${ }^{10}$

\section{The surgical procedure}

Peacock modified the technique of Fasano by exposing the cauda equina rather than at the spinal cord level. He did this to identify the S3 root and thus preserve bladder and bowel function. The laminectomies of the lumbar spine expose bilaterally the roots from the second lumbar to the fifth lumbar vertebra. The surgeon opens the dura and identifies the five to 10 rootlets comprising the posterior roots from $\mathrm{L} 2$ to $S 2$.

Electromyographs record the response to electrical stimulation of each rootlet and also the visible particular muscle that contracts in the lower limb. The criteria for division of a rootlet are the duration, location, and electromyographic pattern of response and the observed muscle contraction. ${ }^{11}$ Usually, the surgeon cuts $25-50 \%$ of the rootlets.

\section{Postoperative care}

All patients have marked weakness in the lower limbs. Recovery is gradual, and functional improvement cannot be expected for six to 12 months. During this period physical therapists apply muscle strengthening and motor control techniques, for example, resistance exercises, cycling, treadmill, electrical stimulation, and electromyographic feedback. ${ }^{2}$ The duration of hospitalisation varies from one to three weeks. Intensive outpatient physical treatment management continues for six to 12 months.

\section{Results}

There have been no operative deaths or infections. No one doubts the diminution of the muscle spasticity and the profound weakness of the lower limbs that gradually 
recovers. Postoperative videotapes of some patients show dramatic improvement.

Although electromyographs show reduction of the prolonged response to stretch of the muscles, preoperative and postoperative electromyographic studies show no change in the primitive and abnormal timing of the muscle activity during gait. ${ }^{12}$ Two follow up gait studies using two dimensional kinematics have shown an increase in the stride length, velocity, and ranges of motion of the hip and knee after surgery..$^{12}$

The only reasonably long term follow up study of seven years was by Arens, Peacock, and Peter. ${ }^{14}$ Of the 51 South African children who had the rhizotomies in 1981 and reported in 1989, 45 were continuing to have physical treatment ('neurodevelopmental'). The major assessment was walking ability, whether they became independent or community walkers. They considered the operation worthwhile in 49 cases and stated that in 24 of these the benefit was 'great'. Overall improvement in function was $82 \% .^{15}$

Others have published results ranging from 13 to 30 cases and with short term follow ups from three months to 14 months. ${ }^{5131617}$ All have done the operation for two groups of patients: one group who have spastic diplegia and can walk and another group with spastic quadriplegia and total body involvement. All report generally good results in reduction of spasticity of the lower limb muscles with no complications, loss of function, or sensory disturbances. Frequently authors make comments on the improvement of hand function and speech, but offer no data as documentation. One study of seven patients attempted to measure improved hand function, but with equivocal results. ${ }^{18}$

\section{Patient selection}

From the review of the literature and the comments of those who are now conducting large prospective studies, the ideal candidate is a child who has spastic diplegia, good intelligence, good balance, voluntary muscular control, and minimal or no muscle or joint contractures or skeletal deformities. Excluded are patients who have athetosis, dystonia, scoliosis, poor trunk balance, and spastic hemiplegia. ${ }^{19}$ The criteria for selection of the patient with total body involvement (spastic quadriplegia) have not been defined and the results seem limited and generalised in the follow up reports.

\section{Critique and controversy}

In a stinging editorial Landau and Hunt questioned not only the unproved efficacy of the procedure, but its neurophysiological rationale as well. They pointed out spasticity was not solely responsible for the functional impairments in cerebral palsy. ${ }^{20}$ They raised many other questions such as patient selection (that is, the 'ideal' child who has spastic diplegia might do just as well without treatment), the scientific basis of the electromyographic response in selecting which rootlet to cut, the need for physical treatment for several years postoperatively, the possible long term effects on sex function, the possible evolution of neuropathic joints, and the cost per case, estimated between $\$ 25000$ and $\$ 100000$. They called for clinical outcome research that has to be an unprejudiced, randomised, multifaceted management and measurement programme. ${ }^{21}$

Unfortunately, lack of interest by and funds from private and public agencies hampered those who initially embarked on the operative procedure from doing elaborate and prospective clinical outcome studies. Now it seems that federal grant funds have been awarded for large multicentre studies.

Cohen and Webster disputed the selectivity of posterior rootlet rhizotomies. While stimulating the rootlets in 22 of their cases, they found no normal responses. ${ }^{22}$ Parallel to this question is the report of Lazareff and associates who cut only the fourth and fifth and the first sacral rootlets in 30 children who had cerebral palsy. With this limited rhizotomy they observed a reduction in spasticity in both the lower and upper limbs and improved function. ${ }^{23}$

Surgeons do not expect that the laminectomy (or laminotomy) of the lumbar spine in children will cause late spinal deformities. They base this prognosis on the long term follow up study by Yasuoka et al. They found a high incidence in children who had cervical and thoracic laminectomies, but none in those who had lumbar laminectomies. ${ }^{24}$ At the 1991 annual meeting of the Pediatric Orthopaedic Society of North America Millis reported a postoperative rapidly progressive hyperlordosis in three cases of 19 patients with spastic quadriplegia.

Rhizotomy does not effect major structural changes in the muscles and joints. Greene and five orthopaedic colleagues reported an increase of subluxation from 25 to $50 \%$ in seven hips in six patients in a mean time of $1 \cdot 1$ years after the selective posterior rhizotomies. ${ }^{25}$ In the South African series 24 needed orthopaedic surgery consisting of 34 procedures. These entailed 28 muscle releases or tendon lengthenings (mainly of the hip adductors, hamstrings, and triceps surae), three derotation femoral osteotomies, one hip open reduction, and one subtalar extra-articular arthrodesis. Twenty six had postoperative valgus deformities of the foot. Nine were waiting for surgery. ${ }^{1+}$ Thus far, it appears that neurosurgery and orthopaedic surgery are not mutually exclusive in the care of those who have cerebral palsy. Perhaps comparisons between the two approaches will be done by those who do comprehensive outcome studies.

\section{EUGENE E BLECK}

Divsion of Orthopaedic Surgery,

Stanford University School of Medicine,

Stanford,

California 94305, USA

1 Peacock WJ, Arens LJ. Selective posterior rhizotomy for the relief of spasticity in cerebral palsy. $S$ Afr Med F 1982; 62: 119-24.

2 Peacock WJ, Arens LJ, Berman B. Cerebral palsy spasticity: selective posterior rhizotomy. Pediatr Neurosci 1987; 13: 61-6.

3 Boop FA, Chadduck WM. Selective posterior rhizotomy for relief of spasticity. 7 Arkansas Med Soc 1991; 87: 512-4.

4 Nazar GB, Linden RD, Badenhausen W. The role of functional dorsal rhizotomy for the treatment of children with spastic cerebral palsy. $\mathcal{F} \mathrm{Ky} \mathrm{Med}$ Assoc 1990; 88: 482-7.

5 Gaskill SJ, Wilkins K, Marlin AE. Selective posterior rhizotomy to treat spasticity associated with cerebral palsy: a critical review. Tex Med 1992; 88: 68-71.

6 Sherrington CS. Decerebrate rigidity and reflex coordination of movements. $\mathcal{F}$ Physiol (Lond) 1898; 22: 319-37.

7 Foerster $\mathrm{O}$. On the indications and results of the excision of the posterior spinal nerve roots in men. Surg Gynecol Gynecol 1913; 16: 463-4.

8 Gros $C$, Ouknine $G$, Vlahovitch $B$, Frerebeau $P$. La radicotomie sélective postérioeure dans le traitement neurochirurgical de l'hypertonie pyramidale. Neurochirurgie 1967; 13: 505-18.

9 Gros C. Spasticity-clinical classification and surgical treatment. Adv Tech Stand Neurosurg 1979; 6: 55-79.

10 Fasano VA, Broggi G, Zeme S. Intraoperative electrical stimulation for functional posterior rhizotomy. Scand f Rehabil Med Suppl 1988; 17: 14954.

11 Newberg NL, Gooch JL, Walker MD. Intraoperative monitory in selective dorsal rhizotomy. Pediatr Neurosurg 1991; 17: 124-7.

12 Cahan LD, Adams JM, Perry J, Beeler LM. Instrumented gait analysis after selective dorsal rhizotomy. Dev Med Child Neurol 1990; 32: 1037-43.

13 Vaughn CL, Berman B, Peacock WJ. Cerebral palsy and rhizotomy. A 3-year follow-up evaluation with gait analysis. F Neurosurg 1991; 74: 178-84.

14 Arens LJ, Peacock WJ. Peter J. Selective posterior rhizotomy: long term follow-up study. Childs Nerv Syst 1989; 5: 148-52.

15 Peacock WJ, Staudt LA. Spasticity in cerebral palsy and the selective posterior rhizotomy procedure. $\mathcal{F}$ Child Neurol $1990 ; 5: 179-85$.

16 Cohen AR, Webster HC. How selective is selective posterior rhizotomy? Surg Neurol 1991; 35: 267-72.

17 Peacock WJ, Staudt LA. Functional outcomes following selective posterior rhizotomy in children with cerebral palsy. $\mathcal{F}$ Neurosurg 1991; 74: 380-5.

18 Kinghorn J. Upper extremity functional changes following selective posterior rhizotomy. Am f Occup Ther 1992; 46: 502-7. 
19 Peacock WJ, Staudt LA. Selective posterior rhizotomy: evolution of theory and practice. Pediatr Neurosurg 1991-2; 17: 128-34.

20 Landau WM, Hunt CC. Dorsal rhizotomy, a treatment of unproven efficacy. f Child Neurol 1990; 5: 174-8.

21 Landau WM, Hunt CC. Letter (re rhizotomy in cerebral palsy). $\mathcal{f}$ Child Neurol 1991; 6: 278.

22 Cohen AR, Webster HC. How selective is selective posterior rhizotomy? Surg Neurol 1991; 35: 267-72.
23 Lazareff JA, Mata-Acosta AM, Garvia-Mendez MA. Limited selective posterior rhizotomy for the treatment of spasticity secondary to infantile cerebral palsy: a preliminary report. Neurosurgery 1990; 27: 535-8.

24 Yasuoka S, Peterson HA, MacCarty CS. Incidence of spinal column deformity after multilevel laminectomy in children and adults. 7 Neurosurg 1982; 57 after $\mathrm{m}$.

25 Green WB, Dietz FR, Goldberg MJ, Gross RH, Miller F, Sussman MD. Rapid progression of hip subluxation in cerebral palsy after selective posterio rhizotomy. $\mathcal{F}$ Pediatr Orthop 1991; 11: 494-7.

\section{Corticosteroid treatment in cystic fibrosis}

Lung damage in cystic fibrosis originates in airway mucosal cells where failure of chloride secretion and enhanced sodium absorption lead to excessive absorption of water. There is loss of the sol phase lining the epithelium and viscid mucous, which interferes with ciliary transport and provides a breeding ground for bacteria, accumulates on the airway wall. In these circumstances the protective and self limiting inflammatory response initiated by pulmonary macrophages is not sufficient to eliminate infection. The continuing presence of bacteria provokes a vigorous systemic inflammatory response that prevents dissemination of infection beyond the lung, but in doing so may contribute to lung injury. Corticosteroid treatment could be beneficial by suppressing those components of the immune response that are damaging the lung.

\section{Unrestrained inflammation in the cystic fibrosis lung}

Polymorphunclear neutrophil leucocytes (PMN) are the principal effector cells of potentially damaging inflammation in the cystic fibrosis lung. ${ }^{1}$ They produce free radicals, proteolytic enzymes, and leukotriene $\mathrm{B}_{4}\left(\mathrm{LTB}_{4}\right)$, which are capable of causing lung destruction and potentiating the inflammatory process. Much of PMN behaviour is governed by immunological signals derived from $T$ cells, $B$ cells, and mononuclear phagocytes in a series of complex interactions.

The main antigen presenting cells are pulmonary macrophages which produce polypeptide signals (cytokines) in response to infectious stimuli. Interleukin (IL)-1 is one of the earliest cytokines generated in the presence of antigen. It is itself a potent chemoattractant and activator of $\mathrm{PMNs},{ }^{2}$ but can also initiate the release of a cascade of other proinflammatory cytokines, including IL-8 and tumour necrosis factor- $\alpha$ (TNF- $\alpha){ }^{3}$ These cytokines have potent chemotactic effects on PMNs and can induce their degranulation. They promote neutrophil margination and their transendothelial passage to sites of active inflammation. ${ }^{47}$ IL-1 also upregulates the expression of high affinity receptors for IL-2 on T cells and activates them by stimulating the release of IL- $2 .{ }^{8}$

Clinical studies in cystic fibrosis suggest that these cytokines are participating in the inflammatory response. Neutrophils are the predominant cell recovered from lavage fluid in patients with cystic fibrosis. They are present in quantities that correspond with concentrations of IL-1 $\beta$ and IL-8.910 Plasma IL-1 $\alpha$ and TNF- $\alpha$ are also increased; concentrations of the latter correlate with those of neutrophil elastase antiprotease complexes." ${ }^{.1}$ Evidence for $T$ cell activation is provided by the observation that soluble IL-2 receptors are raised in sera from patients with cystic fibrosis. ${ }^{12}$ Histological studies have demonstrated that significant numbers of $T$ and $B$ lymphocytes are also present in the airway in cystic fibrosis. ${ }^{13}$ IL-1 and IL-2 may have a synergistic effect on B cells, attracting them to sites of inflammation and promoting their differentiation into mature plasma cells capable of producing immunoglobulin. ${ }^{14}$
Hypergammaglobulinaemia $G$ frequently accompanies chronic pseudomonas infection in children with cystic fibrosis and is associated with a poorer prognosis. ${ }^{15}$ Immunoglobulin $\mathrm{G}$ is the important isotype for bacterial opsonisation; however, in cystic fibrosis there may be a mismatch between the subclass produced and its Fc receptors on macrophage/ monocytes. ${ }^{16}$ Although the opsonic capability of certain cystic fibrosis IgG subclasses may be defective, their ability to form immune complexes with bacterial antigens is preserved. Immune complexes are present in sputum and the circulation of patients with cystic fibrosis and are capable of local complement activation. ${ }^{17}{ }^{18}$ Fick et al found increased concentrations of the powerful neutrophil chemoattractant (C5a) in cystic fibrosis lavage fluid that correlated with its elastolytic activity. ${ }^{19}$ In addition, immune complexes and C5a can further stimulate macrophages to produce other potent PMN chemoattractants, including $\mathrm{LTB}_{4}, \mathrm{IL}-8$, and TNF- $\alpha .{ }^{20}$

Neutrophil elastase may be an important regulatory enzyme of the inflammatory response; it is produced in quantities sufficient to overwhelm local antiprotease systems. Sputum elastolytic activity increases during infective exacerbations and correlates significantly with pulmonary disease severity. ${ }^{191}$ Neutrophil elastase may synergise with exoproteases derived from mucoid strains of Pseudomonas aeruginosa to degrade elastin and other components of lung connective tissue. Evidence for lung proteolysis is suggested by studies that demonstrate raised urinary desmosine concentrations (cross linking amino acids in elastin) in those with cystic fibrosis. ${ }^{22}$ Neutrophil elastase may also have an immunomodulatory role. Free neutrophil elastase may render bacterial opsonophagocytosis defective by degrading interactive sites on complement components $\left(C_{3}\right.$ and $\left.C_{5}\right)$, destroying complement receptors on phagocytes, and cleaving the Fc portion of immunoglobulin and immune complexes. ${ }^{23}$ Yet these molecules retain their respective abilities to attract neutrophils, activate complement, and induce cytokine expression.

When colonisation with mucoid strains of $P$ aeruginosa occurs, it presents additional problems for host defence mechanisms, which render it virtually impossible to eradicate. Its mucoid layer protects it from opsonisation and phagocytosis by host macrophages. Exoproteases derived from mucoid strains of $P$ aeruginosa can cleave $\mathrm{CD}_{4}$ receptors on $\mathrm{T}$ lymphocytes, inhibit human neutrophil chemiluminescence, and inactivate cytokines (IL-1 and IL-2). ${ }^{24}$ Thus, the inflammatory cycle is perpetuated without clearance of the offending organism. Respiratory allergy and specific hypersensitivity to Aspergillus fumigatus may place an additional inflammatory burden on the already compromised cystic fibrosis lung. Although they are potentially amenable to corticosteroid treatment, their inflammatory mechanisms are too detailed to be discussed in the present annotation.

High concentrations of cyclo-oxygenase products (thromboxanes and prostaglandins) ${ }^{25} 26$ and lipoxygenase 